\title{
Estágio supervisionado em época de Covid-19: experiência da Biblioteconomia da Unochapecó
}

\section{Supervised internship in Covid-19 time: Unochapecó Library Science experience}

\author{
Jéssica Bedin ${ }^{1}$ \\ ${ }^{1}$ Universidade Comunitária de Chapecó (Unochapecó); Universidade Federal de Santa Catarina (UFSC), Santa Catarina, Brasil. ORCID: \\ https://orcid.org/0000-0003-2324-4246
}

Autor para correspondência/Mail to: Jéssica Bedin, jessicabedin06@gmail.com

Recebido/Submitted: 29 de agosto de 2020; Aceito/Approved: 22 de novembro de 2020

Copyright (c) 2020 Souza. Todo o conteúdo da Revista (incluindo-se instruções, política editorial e modelos) está sob uma licença Creative Commons AtribuiçãoNãoComercial-Compartilhalgual 3.0 Não Adaptada. Ao serem publicados por esta Revista, os artigos são de livre uso em ambientes educacionais, de pesquisa e não comerciais, com atribuição de autoria obrigatória. Mais informações em http://revistas.ufpr.br/atoz/about/submissions\#copyrightNotice.

\begin{abstract}
Resumo
Introdução: Relatar a experiência do Estágio Supervisionado do Curso de Biblioteconomia da Unochapecó que, devido à pandemia da Covid-19, aconteceu de forma remota é o objetivo que norteia este short paper. Método: Por uma abordagem exploratória e descritiva, com a aplicação de pesquisa-ação se realiza a análise mais aprofundada do fenômeno, que contou com 15 estudantes-estagiários distribuídos em cinco bibliotecas. Resultados: Os supervisores locais evidenciaram vantagens como: as propostas de melhorias permitiram aos estudantes-estagiários pensar em produtos/serviços por um ângulo diferente que provavelmente não seria possível se o estágio tivesse ocorrido de forma presencial; a possibilidade de dar total atenção aos estudantes-estagiários, sendo que se estivessem realizando o estágio presencialmente havia outras atividades da rotina. Os estudantes-estagiários estiveram convergentes quanto: à oportunidade de utilizar novas ferramentas, de encarar os desafios e de se reinventar; capacidade de adaptação do curso e dos bibliotecários(as) para atender seus usuários; momentos de debate e reunião com toda a equipe de trabalho, o que se considera que seria necessário, mas inviável para a instituição que nos acolheu se todos os serviços estivessem a pleno vapor. Conclusão: Apesar dos estudantes-estagiários não vivenciarem a rotina tradicional de uma biblioteca que envolve o contato com os usuários, a dinâmica utilizada possibilitou criar uma sintonia entre os estudantes-estagiários, os supervisores locais e a professora supervisora, o que facilitou a interação e os debates sobre as rotinas e as atividades desenvolvidas nas bibliotecas, viabilizando a construção das propostas de melhorias significativas para as bibliotecas.
\end{abstract}

Palavras-chave: Estágio Supervisionado; Biblioteconomia; Unochapecó; Coronavírus; Pandemia Covid-19.

\begin{abstract}
Introduction: To report the experience of the Supervised Internship of the Unochapecó Library Science, which due to the Covid-19 pandemic happened remotely, is the objective that guides this short paper. Method: Through an exploratory and descriptive approach, with the application of action-research, a more in-depth analysis of the phenomenon is carried out, which included 15 students distributed in five libraries. Results: The local supervisors showed advantages such as: the improvement proposals allowed the students to think about products/services from a different angle that would probably not have been possible if the internship had taken place in person; the possibility of giving total attention to the students, being that if they were carrying out the internship in person there were other routine activities. The interns converged on: the opportunity to use new tools, to face challenges and reinvent themselves; the ability to adapt the course and the librarians to serve its users; moments of debate and meeting with the entire work team, which is considered necessary but not feasible for the institution that welcomed us if all services were at full steam. Conclusion: Although students do not experience the traditional routine of a library that involves contact with users, the dynamics used made it possible to create harmony between students, local supervisors, and the supervising teacher, which facilitated interaction and debates about the routines and activities developed in libraries, making it possible to build proposals for significant improvements for libraries.
\end{abstract}

Keywords: Supervised Internship; Librarianship; Unochapecó; Coronavirus; Covid-19 Pandemic.

\section{INTRODUÇÃO}

O cenário da pandemia da Covid-19 trouxe inúmeros desafios, entre eles a impossibilidade da realização do Estágio Supervisionado in loco, conforme portaria No 544 , de 16 de junho de 2020, que dispõe sobre a substituição das aulas presenciais por aulas em meios digitais enquanto durar a situação de pandemia (Ministério da Educação, 2020). Deste modo, buscaram-se alternativas para promover o contato dos estudantes-estagiários com a realidade profissional ao aproximar teoria e prática com a aplicação das competências na proposta de soluções de problemas em unidades de informação a partir de soluções criativas e inovadoras.

A proposta teve como base a estrutura do Estágio Supervisionado do Curso de Biblioteconomia da Universidade Comunitária da Região de Chapecó (Unochapecó), configurado na modalidade a distância, que apresenta como objetivo "a formação de profissionais capazes de compreender as necessidades de informação dos mais variados públicos", com vistas a auxiliar nas respostas e na orientação por meio da percepção e organização estratégica das informações (Universidade Comunitária da Região de Chapéco, 2020).

Diante dessa perspectiva, surgiram as seguintes indagações: 1) Como realizar a disciplina de Estágio Supervisionado em meio à pandemia do Coronavírus? 2) Quais mecanismos poderiam ser utilizados para propiciar aos estudantes-estagiários uma real experiência de estágio? 3) Como seriam encaminhadas as instruções para 
estudantes-estagiários e instituições envolvidos no processo? 4) De que forma poderia ser realizada a avaliação do processo por parte das instituições e dos estudantes-estagiários? Nesse sentido, o objetivo é relatar a experiência do Estágio Supervisionado do Curso de Biblioteconomia da Unochapecó com a apresentação dos processos de elaboração e concretização.

\section{REFERENCIAL TEÓRICO}

Durante a formação profissional, o estágio é um dos momentos mais esperados pelos estudantes, justamente por aliar a teoria à prática, pois, de acordo com Pimenta (2003), o estágio é um processo de aprendizagem que permite a aproximação dos estudantes com os ambientes de atuação na Biblioteconomia.

Para Alves (2013, p. 833-834), o estágio é "um espaço de experimentação, mas para que este se concretize, é necessário que espelhe o conteúdo teórico transmitido no curso e o complementar pela oferta de oportunidades, sob a supervisão de profissionais competentes e sobe orientação de professores da IES".

A atividade de estágio é regulamentada pela Lei 11.788 de 25 de setembro de 2008. Em seu Art. $1 .^{\circ}$ evidencia que:

Estágio é ato educativo escolar supervisionado, desenvolvido no ambiente de trabalho, que visa à preparação para o trabalho produtivo de educandos que estejam frequentando o ensino regular em instituições de educação superior [...]. O estágio visa ao aprendizado de competências próprias da atividade profissional e à contextualização curricular, objetivando o desenvolvimento do educando para a vida cidadã e para o trabalho (Lei 11.788, 2008).

A importância do estágio, segundo Alves (2013), está ligada às novas exigências e desafios que surgem na sociedade, fazendo com que os profissionais desenvolvam, além das capacidades técnicas, atitudes de liderança, criatividade, ética e adaptabilidade perante rápidas mudanças, sejam elas informacionais, sociais ou de cenários. Neste sentido, destaca-se o cenário da pandemia da Covid-19, que impossibilitou as vivências sociais devido a questões de saúde pública, mas que também exigiu das bibliotecas formas de manter contato, informar e atender as demandas de suas comunidades que se encontravam isoladas.

Dessarte, ao relacionar os desafios eminentes da sociedade com o perfil dos egressos estabelecido pelo Conselho Nacional de Educação do Ministério da Educação (2001), nota-se o alinhamento ao abordar que:
A formação do bibliotecário supõe o desenvolvimento de determinadas competências e habilidades e o domínio dos conteúdos da Biblioteconomia. Além de preparados para enfrentar com proficiência e criatividade os problemas de sua prática profissional, produzir e difundir conhecimentos, refletir criticamente sobre a realidade que os envolve, buscar aprimoramento contínuo e observar padrões éticos de conduta, os egressos dos referidos cursos deverão ser capazes de atuar junto a instituições e serviços que demandem intervenções de natureza e alcance variados: bibliotecas, centros de documentação ou informação, centros culturais, serviços ou redes de informação, órgãos de gestão do patrimônio cultural (Ministério da Educação, 2001, não paginado).

A necessidade de contribuir com uma realidade crítica faz com que se adotem formas de estimular e compreender eventos com base na problematização de uma realidade e nos conhecimentos disponíveis, permitindo, assim, que o estudante seja o protagonista no processo, apto a construir pontes entre o mundo das ideias e a realidade (Fujino \& Vasconcelos, 2011; Rodrigues, 2002). Ao relacionar com o cenário crítico que foi desencadeado pela pandemia da Covid-19, ocorreu a necessidade de compreender tal evento e os problemas gerados, a fim de mobilizar conhecimentos e propor soluções inovadoras para que os estágios pudessem ser viabilizados, colocando os estudantes-estagiários enquanto protagonistas.

\section{PROCEDIMENTOS METODOLÓGICOS}

Caracteriza-se este relato como exploratório e descritivo, a partir de uma pesquisa-ação que traz a análise mais aprofundada de um fenômeno, aqui visualizado na realização remota de estágios requeridos na disciplina de Estágio Supervisionada do Curso de Biblioteconomia da Unochapecó. A proposta teve como base os objetivos do Estágio Supervisionado:

I - possibilitar aos estudantes-estagiários do curso de Biblioteconomia compreensão do conhecimento técnico-científico, aprendidos e/ou trabalhados no curso, visando seu processo de formação profissional;

II - inserir o estudante-estagiário no campo profissional, desenvolvendo habilidades e competências, produzindo novos saberes, contribuindo, com uma prática criativa e inovadora, para o encaminhamento de soluções aos problemas percebidos;

III - proporcionar ao estudante-estagiário a vivência, compreensão, análise e a intervenção na realidade de sua formação profissional; IV - apropriar aos estudantes-estagiários elementos da realidade social 
tomada como objeto de reflexão e intervenção, aprofundando o conhecimento da interação da área específica de atuação com questões de âmbito macrossocial;

V - contribuir com o processo de avaliação permanente do Projeto Pedagógico do Curso de graduação de Biblioteconomia (bacharelado) na modalidade de Educação a Distância (Universidade Comunitária da Região de Chapéco, 2017).

Utilizou-se da metodologia design thinking para conduzir a construção das propostas de melhoria nas bibliotecas. De acordo com a IDEO (2017, p. 7), o design thinking é "uma abordagem criativa ou uma série de etapas que ajudarão a desenhar, satisfatoriamente, soluções para a sua biblioteca". Além disso, permite ver os problemas como oportunidades e ajuda a desenvolver confiança no processo de criar soluções transformadoras.

Quanto às técnicas utilizadas para a coleta dos dados, após o seminário de estágio foi enviado um questionário aos estudantes-estagiários, avaliando as seguintes variáveis: atividades desenvolvidas na disciplina; orientações administrativas e orientações das atividades encaminhadas pela professora; acompanhamento do supervisor local durante o estágio; carga horária do estágio; ferramentas utilizadas para mediar os encontros e a interação com a equipe da biblioteca; experiência e aprendizado durante o estágio; e vantagens e perdas percebidas na realização do estágio remoto em frente à pandemia da Covid-19. Por fim, foi disponibilizado um espaço para registrar depoimentos, comentários e sugestões.

E no questionário para os bibliotecários supervisores locais foram avaliadas as seguintes variáveis: envolvimento do estagiário nas atividades do estágio; orientações das atividades encaminhadas pela professora supervisora; distribuição da carga horária; ferramentas utilizadas para mediar os encontros e a interação com a equipe da biblioteca; experiência e aprendizado ao receber os estagiários; vantagens e perdas percebidas na realização do estágio remoto em frente à pandemia da Covid-19. Por fim, disponibilizou-se um espaço para registrar depoimentos, comentários e sugestões.

\section{RESULTADOS}

Após aprovação na reunião de Colegiado do Curso, realizaram-se os encaminhamentos práticos. Com as sugestões de locais recebidas dos estudantes-estagiários, verificou-se quais bibliotecas estavam atendendo de forma presencial e/ou remota. A professora da disciplina entrou em contato para conhecer a realidade dessas bibliotecas e a possibilidade de realizar o estágio de forma remota, no intuito de contribuir com os problemas que surgiram com a pandemia. As bibliotecas de cinco instituições se colocaram à disposição para acompanhar os estudantes-estagiários durante os estágios, três bibliotecas públicas municipais e duas universitárias.

Em reunião com os estudantes-estagiários, obteve-se unanimidade no aceite de realizarem o estágio de forma remota, tendo em vista que se tratava de formandos e estes compreenderam a importância de suas contribuições com o cenário atual, buscando soluções para os problemas relacionados à informação a partir dos conhecimentos da Biblioteconomia.

Registra-se que os estudantes-estagiários estavam na expectativa pelo estágio in loco, tendo em vista que teriam contato com os profissionais e com as rotinas das bibliotecas de forma presencial, experiência única durante a graduação e geradora de muitos aprendizados.

Centralizar os estágios em cinco bibliotecas e organizar a dinâmica de trabalho em grupos teve o intuito de aproveitar o plano de trabalho, que contou com a sistematização e apresentação das rotinas, projetos e do próprio cenário de cada biblioteca. Tal organização facilitou a condução dos estágios, além de possibilitar aos estudantes-estagiários o compartilhamento de ideias com os colegas durante o estágio, não se sentindo sozinhos no processo.

O relatório de estágio permaneceu sendo desenvolvido de forma individual, apesar da organização e condução das atividades em grupo. A distribuição dos estudantes-estagiários por instituições pode ser observada no Quadro 1:

\begin{tabular}{|c|c|c|}
\hline Quantidade de Estudantes-estagiários & Tipo de biblioteca & Cidade/Estado \\
\hline 4 & Universitária Comunitária & Chapecó/SC \\
\hline 4 & Pública Municipal & Pinhalzinhocó/SC \\
\hline 2 & Universitária Estadual & Toledo/PR \\
\hline 4 & Pública Municipal & Curitibanos/SC \\
\hline 1 & Pública Municipal & \\
\hline
\end{tabular}

Quadro 1. Quantidade de estudantes-estagiários por tipo de biblioteca e cidade referentes à disciplina de Estágio Supervisionado do Curso de Biblioteconomia da Unochapecó.

Fonte: Bedin (2020).

Com os locais definidos e o direcionamento dos estudantes-estagiários, estabeleceram-se algumas etapas para 
conduzir a sistematização e construção dos planos de trabalhos, bem com as datas de início e término do estágio, conforme Quadro 2.

\begin{tabular}{|c|l|}
\hline Etapa & Descrição \\
\hline 1 & $\begin{array}{l}\text { Reunião com os(as) bibliotecários(as) para conhecer os locais de estágio e entender a organização } \\
\text { de trabalho e problemas enfrentados durante o distanciamento social. }\end{array}$ \\
\hline 2 & $\begin{array}{l}\text { Reunião com os(as) bibliotecários(as) para conhecer os locais de estágio e entender a organização } \\
\text { de trabalho e problemas enfrentados durante o distanciamentoElaboração do Plano de trabalho } \\
\text { por parte dos(as) bibliotecários(as) e acompanhamento da professora supervisora. }\end{array}$ \\
\hline 3 & $\begin{array}{l}\text { Reunião das equipes para integração e apresentação da dinâmica de estágio remoto (25 a 29 de } \\
\text { maio). }\end{array}$ \\
\hline 4 & Início dos estágios a partir de 1 de junho. \\
\hline 5 & Finalização dos estágios até 31 julho. \\
\hline 7 & $\begin{array}{l}\text { Entrega dos relatórios de estágio em 31 de julho. } \\
\text { Seminário da disciplina para compartilhar as experiências e aprendizados com todos os } \\
\text { estudantes-estagiários, supervisores locais e professora supervisora em 18 de agosto. }\end{array}$ \\
\hline 8 & Avaliação do processo remoto dos estágios por parte das instituições e estudantes-estagiários. \\
\hline
\end{tabular}

Quadro 2. Etapas e suas descrições para a realização dos estágios da disciplina de Estágio Supervisionado do Curso de Biblioteconomia da Unochapecó.

Fonte: Bedin (2020).

Quanto ao plano de trabalho, este variou de acordo com a rotina de cada biblioteca, no entanto, todas seguiram alguns padrões como: momentos para compartilhar informações e apresentar o cenário da biblioteca; encontros remotos para conhecer as rotinas, setores, atividades e projetos da biblioteca; análise do cenário da biblioteca em tempos de distanciamento social, limitações e possibilidades de atuação; identificação de problemas informacionais e proposta de solução como produtos do estágio; e compartilhamento da experiência com o grupo.

Para viabilizar a interação entre os envolvidos, utilizou-se das ferramentas: Agenda Google, para organizar os encontros; Google Meet, para reuniões online; apresentação de Power Point (.ppt) e sistemas da biblioteca; e ferramentas de gestão como o design thinking para propor soluções inovadoras para as bibliotecas.

Ao desenvolver propostas de melhorias viáveis e que pudessem contribuir de fato com a realidade das bibliotecas, a professora da disciplina utilizou do design thinking para conduzir os trabalhos e integrar os estudantes-estagiários com as equipes das bibliotecas.

Para finalizar a disciplina, realizou-se um seminário via Google Meet com os bibliotecários supervisores e estudantes-estagiários, momento muito rico para compartilhar as propostas de melhoria e as experiências vivenciadas durante o estágio supervisionado remoto. Após o seminário, a professora enviou questionários de avaliação tanto para os estudantes-estagiários, como para os bibliotecários supervisores.

Com base na avaliação respondida pelos supervisores locais, evidenciaram-se algumas vantagens percebidas, como: propostas de melhorias construídas durante o estágio remoto que permitiram aos estudantes-estagiários pensar em produtos/serviços por um ângulo diferente que provavelmente não seria possível se o estágio tivesse ocorrido de forma presencial; a possibilidade de dar total atenção aos estudantes-estagiários, o que não seria possível se estivessem realizando o estágio presencialmente, pois haveria outras atividades da rotina (trabalhos que não se pode deixar de fazer, telefonemas, reuniões etc.).

Em relação à experiência e aprendizagem por parte dos(as) bibliotecários(as) durante o estágio remoto, destacamse alguns trechos de depoimentos:

Biblio 1: A experiência foi muito enriquecedora. No começo ficamos assustadas, pensamos que não seria fácil. Mas, fomos surpreendidas! Os alunos eram muito dedicados, presentes e participativos. Acho que conseguimos despertar alguns insights em cada um deles, o que vem a agregar muito para nossa profissão.

Biblio 2: A condução do estágio foi realizada de forma muito clara e objetiva. Isso tranquilizou o bibliotecário supervisor no local onde o estágio aconteceu. O novo modo do estágio trouxe muitas inseguranças no início, por isso a condução da professora supervisora foi determinante para o sucesso. Os alunos demonstraram real interesse no estágio e "aproveitaram"o momento para questionar bastante e se inteirar o máximo possível do espaço onde realizaram o estágio. É sempre muito gratificante receber estagiários na Biblioteca, pois permite uma troca muito interessante e também a oportunidade de revisitar o próprio trabalho que já desenvolvemos, mas que as vezes no dia a dia não nos damos conta e o estágio possibilita este exercício de relatar as atividades já desenvolvidas pela Biblioteca e vislumbrar novas possibilidades com os estagiários. 
Biblio 3: Para mim o estágio foi muito produtivo, foi uma troca mútua de conhecimento onde em cada orientação, os questionamentos me fazia estudar mais, pesquisar mais para poder sanar as dúvidas deles, e também exercitam a minha criatividade, onde em cada orientação eu precisava abstrair os conceitos que para mim são comuns, mas para eles são novidade.

Na avaliação realizada pelos estudantes-estagiários, foi possível identificar algumas convergências, como: a oportunidade de utilizar novas ferramentas, de encarar os desafios e de se reinventar, fazer de um modo diferente, seguir novos caminhos; capacidade de adaptação do curso de Biblioteconomia e dos profissionais bibliotecários para continuar a atender seus usuários da melhor forma possível; adaptação e aprimoramento de serviços já existentes e criação de novas formas de estágio (remoto); momentos de debate, reflexão e reunião de toda a equipe de trabalho, o que se considera que seria necessário, mas inviável para a instituição que nos acolheu se todos os serviços estivessem a pleno vapor e boa organização do tempo. Para registrar a experiência e aprendizagem por parte dos(as) estagiários(as) durante o estágio remoto, destacam-se alguns trechos de depoimentos:

Estudante-estagiário 1: Foi ótima! Estava bastante ansiosa para a chegada desta etapa e, apesar de acontecer de forma diferente, aproveitei cada momento, seja online, seja presencial, para aprender, para tirar dúvidas, para esclarecer pontos, para agregar valor ao meu crescimento profissional.

Estudante-estagiário 2: A minha experiência de estágio foi maravilhosa, aprendi muita coisa com o meu supervisor. Ele foi muito dedicado e não mediu esforços para auxiliar a mim e aos meus colegas que realizaram o estágio remotamente. Aprendi as rotinas de catalogação no Pergamum, setor de Serviço de Referência, seleção e higienização de materiais, ordenação de acervo, em suma, muitas coisas do dia a dia do Bibliotecário.

Estudante-estagiário 3: Minha experiência em relação ao estágio foi ótima. Muito proveitosa. Puder conhecer um pouco sobre todos os setores da Biblioteca Pública. As trocas de ideias e experiências com os colegas e bibliotecários contribuiu para o aprendizado que, com certeza, levarei para minha vida profissional.

Estudante-estagiário 4: Inspiração, o estágio proporcionou uma experiência enriquecedora que agregou muito na minha formação.

Estudante-estagiário 5: Este estágio veio com mais algumas inseguranças do que o normal, por estarmos passando pela pandemia, além dos anseios de colocar em prática o que aprendemos na teoria, teve a preocupação com o coronavírus. No entanto foi uma experiência única, com algumas restrições, porém com ganho de experiência e troca de conhecimentos que contribuirão muito ao longo da carreira. O contato com outras pessoas da área da biblioteconomia foi muito rico, sempre tive o contato apenas com professores do curso e perceber o quanto os profissionais são unidos e que podemos contar com essa troca foi muito importante.

Estudante-estagiário 6: Foi ótimo, adorei essa experiência, no início achamos que não ia dar muito certo, mas as bibliotecárias e a professora foram de uma prestatividade que nos acolheu e animou, acredito que pra elas também serviu de ponto inicial e experiência para novos estagiários nesta modalidade, aprendi muito, só tenho a agradecer e querer bis.

Registraram-se também as percepções quanto às perdas por parte de ambos, estagiários(as) e bibliotecários(as): contato físico, seja com a equipe da biblioteca, seja com a comunidade atendida; vivência da unidade de informação funcionando normalmente com a presença dos usuários no espaço; o processo de catalogação com um contato mais próximo para orientar, utilizando de diferentes recursos informacionais.

\section{CONSIDERAÇÕES FINAIS}

Compartilhar ações práticas é fundamental para o desenvolvimento técnico e científico de uma área, Assim, cumpriu-se o objetivo ao relatar a experiência do Estágio Supervisionado do Curso de Biblioteconomia da Unochapecó ao apresentar os processos de elaboração e concretização desta atividade.

Apesar dos estudantes-estagiários não vivenciarem a rotina tradicional de uma biblioteca que envolve o contato com os usuários, a dinâmica utilizada possibilitou criar uma sintonia entre os estudantes-estagiários, os supervisores locais e a professora supervisora, o que facilitou a interação e os debates sobre as rotinas e as atividades desenvolvidas nas bibliotecas.

Discussões que permitiram uma aproximação com o cenário das bibliotecas, suas potencialidades e fragilidades. Informações estas fundamentais para a construção de propostas de melhorias, realizadas de forma colaborativa entre os(as) estagiários(as) e a equipe da biblioteca a partir da aplicação da metodologia design thinking.

No que tange às dificuldades encontradas, pode-se citar que poucas bibliotecas estavam atuando de forma semipresencial ou remota e, quando estavam em atividades, alguns profissionais não se sentiam aptos a conduzir o estágio de forma remota. 
Como futuros trabalhos, visualiza-se a possibilidade de compartilhar a construção das propostas de melhorias a partir da aplicação da metodologia do design thinking com as equipes. As propostas de melhoria abrangeram o desenvolvimento do regimento interno, política de indexação, de formação e desenvolvimento de coleções, além da estruturação de ações e serviços para aproximar a biblioteca de suas comunidades.

\section{AGRADECIMENTOS}

Deixo registrada a minha admiração pelas bibliotecárias Caroline Miotto Pecini, Gabriella Joana Zorzetto, Jackellynni Michelle Ferreira de Barros, Marcia Rodrigues da Silva, Marilene Franceschi, Viviane Formighieri Muller, Wilfrelena Maria Martins Leme Marques Pallone e o bibliotecário Hamã Candido Carvalho Lopes e suas respectivas bibliotecas e instituições por terem aceito o desafio de acompanhar e orientar o estágio remoto em tempos tão difíceis e incertos. Aos estudantes por se prontificarem a exercitar os conhecimentos da área e pela responsabilidade social na realização do estágio em uma nova configuração imposta pela Covid-19. Aos colegas que compõem o Colegiado do Curso de Biblioteconomia da Unochapecó por contribuírem, acreditarem e aprovarem a realização dos estágios remotos. 


\section{REFERÊNCIAS}

Alves, M. A. M. (2013). Estágio: utopia ou realidade? a experiência da coordenação de estágio da escola de biblioteconomia da unirio pratica training: utopia or reality? the experience report of practical training coordination of the library science course at unirio. Revista ACB, 18(1), 829845. Recuperado de http://hdl.handle.net/20.500.11959/ brapci/ 76700

Bedin, J. (2020). [Plano de aula da disciplina de Estágio supervisionado do Curso de Biblioteconomia a Unochapecó]. Chapecó.

Brasil. (2008). Lei $n^{\circ} 11.788$, de 25 de setembro de 2008. Diário Oficial [da] República Federativa do Brasil, Brasília, DF, 26 de set. de 2008. Recuperado de https://www.planalto .gov.br/ccivil_03/_ato2007-10/2008/lei/111788.htm

Fujino, A., \& Vasconcelos, M. d. O. (2011). Estágios: reflexões sobre a ação didático-pedagógica na formação do profissional da informação. CRB8 Digital, 4(1). Recuperado de http://hdl.handle.net/20.500.11959/brapci/9686

IDEO. (2017). Design Thinking para bibliotecas: um toolkit para design centrado no usuário. São Paulo: IDEO. Recuperado de https://tonarede.org.br/wp-content/uploads/ 2017/09/Design-Thinking-para-Bibliotecas-Toolkit.pdf

Ministério da Educação. (2001). Diretrizes Curriculares Nacionais dos cursos de Filosofia, História, Geografia, Serviço Social, Comunicação Social, Ciências Sociais, Letras, Biblioteconomia, Arquivologia e Museologia. Parecer CNE/CES n. 492, de 04 de julho de 2001. Diário Oficial [da] República Federativa do Brasil, Brasília, DF, 09 jul. 2001. Seção 1, Parte 50. Recuperado de http://portal.mec.gov.br/conselho-nacional-de-educacao/ atos-normativos--sumulas-pareceres-e-resolucoes?id=12816

Ministério da Educação. (2020). Portaria $n^{\circ}$ 544, de 16 de junho de 2020. Dispõe sobre a substituição das aulas presenciais por aulas em meios digitais, enquanto durar a situação de pandemia do novo coronavírus - Covid-19, e revoga as Portarias MEC n ${ }^{\circ} 343$, de 17 de março de 2020, $\mathrm{n}^{\circ} 345$, de 19 de março de 2020 , e $\mathrm{n}^{\circ} 473$, de 12 de maio de 2020. Diário Oficial da União, Brasília, DF, 17 jun. 2020. p. 62. Recuperado de https://www.in.gov.br/web/dou/-/ portaria-n-544-de-16-de-junho-de-2020-261924872

Pimenta, S. G. (2003). Estágio, trabalho e educação. In Relatório do ii encontro nacional estágios, ensino superior e mercado de trabalho: Perspectivas para o futuro. São Paulo: ForGAD.

Rodrigues, M. E. (2002). A pesquisa como princípio educativo para a formação de profissionais de informação. In M. L. P. Valentim (Ed.), Formação do profissional da informação (p. 89-101). São Paulo: Polis.

Universidade Comunitária da Região de Chapéco. (2017). Conselho Universitário. Resolução no 062/CONSUN/2017. Aprova a alteração do regulamento de estágios curriculares obrigatório e não obrigatório do curso de biblioteconomia (bacharelado - modalidade de educação a distância). Atos oficiais Unochapecó, Chapecó, 28 ago. 2017. Recuperado de https://atosoficiais.com.br/unochapeco/resolucao-consun -n-62-2017-aprova-a-alteracao-do-regulamento-de-estagios -curriculares-obrigatorio-e-nao-obrigatorio-do-curso-de -graduacao-em-biblioteconomia-bacharelado-modalidade -de-educacao-a-distancia?origin=instituicao\&q= regulamento\%20de\%20est\%C3\%A1gio\%20biblioteconomia

Universidade Comunitária da Região de Chapéco. (2020). Biblioteconomia na Unochapecó. Recuperado de https:// www.unochapeco.edu.br/biblioteconomia
Bedin, J. (2020). Estágio supervisionado em época de Covid-19: experiência da Biblioteconomia da Unochapecó. AtoZ: novas práticas em informação e conhecimento, 9(2), 241 - 247. Recuperado de: http:// dx.doi.org/10.5380/atoz.v9i2.76155 